\title{
UNDERSTANDING THE EFFECT OF CO-WORKER SUPPORT ON CONSTRUCTION SAFETY PERFORMANCE FROM THE PERSPECTIVE OF RISK THEORY: AN AGENT-BASED MODELING APPROACH
}

\author{
Tingting JI(1) ${ }^{1}$, Hsi-Hsien WEI(1) ${ }^{*}$, Jiayu CHEN (i) 2 \\ ${ }^{1}$ Department of Building and Real Estate, The Hong Kong Polytechnic University, Hong Kong \\ ${ }^{2}$ Department of Architecture and Civil Engineering, City University of Hong Kong, Hong Kong
}

Received 10 May 2018; accepted 22 October 2018

\begin{abstract}
Co-worker safety support has been given prominence in manufacturing and transportation field for its positive effect on individual workers' safety; however, there is little evidence to show if such supporting role of co-workers is significant in improving project-level safety performance in construction workplace. This study adopts agent-based modeling $(\mathrm{ABM})$ to understand the effectiveness of two distinct co-worker-safety-support actions on the safety performance of a construction project. Based on the risk theory, the ABM model simulates a construction site where worker agents reinforce steel bars with the likelihood of suffering crane-related incidents. The results indicate that both co-worker-support actions can significantly reduce the occurrence of nonfatal incidents but shows little influence in fatal incidents, and in reducing high-severity incidents, the action of warning peers to leave the hazardous area has the same effectiveness as reminding peers to wear Personal Protective Equipment. The present study provides a fresh insight into the safety-related role of coworkers: not only reveals how the local-level effects of co-workers' safety assistance emerge the system-level consequences, but demonstrates the effectiveness of specific peer-support actions on three levels of construction safety performance, and thereby extends our existing body of knowledge on co-worker safety support in the construction field.
\end{abstract}

Keywords: agent-based modeling, construction safety, construction management, co-worker support.

\section{Introduction}

Occupational safety has emerged as one of the central concerns in the construction industry, as a result of high workplace casualties: in the United States in 2015, 937 construction workers died on the job (BLS, 2016a). This was not only the largest number of fatalities in any one U.S. industry but nearly triple the death rate of the secondlargest one, manufacturing (BLS, 2016a). To facilitate construction contractors' adoption of more effective methods for reducing workplace injuries and fatalities, a considerable body of research has focused on factors that can affect construction-safety performance. Traditionally, such work has been based on particular projects, and has ranked safety factors based on contractors' opinions (AbdulRashid, Bassioni, \& Bawazeer, 2007; Chan, 2005; Cheng, Ryan, \& Kelly, 2012; Jannadi \& Bu-Khamsin, 2002; Sawacha, Naoum, \& Fong, 1999) or on analysis of the targeted projects' actual safety records (Hinze, Hallowell, \& Baud, 2013; Jaselskis, Anderson, \& Russell, 1996; Tam \& Fung, 1998). However, the project-specificity of these studies' methods renders the generalizability of their findings to other construction projects questionable. Moreover, they have mainly focused on organizational-level factors at the expense of personnel-level ones such as co-worker safety support - a safety-related assistance provided by workers to their colleagues in workplaces (McFadden, 2015). Despite sufficient empirical evidence from the manufacturing and transportation sectors has indicated that co-worker safety support can positively affect the safety-related behaviors, attitudes, and perceptions of workers (Brondino, Silva, \& Pasini, 2012; McFadden, 2015; Meliá, Mearns, Silva, \& Lima, 2008; Tucker, Chmiel, Turner, Hershcovis, \& Stride, 2008; Turner, Chmiel, Hershcovis, \& Walls, 2010; Watson, Scott, Bishop, \& Turnbeaugh, 2005), it is still unclear that whether co-worker safety support can make a difference to the objective safety outcomes of a project or a company. Especially in the construction field, it is often concerned that whether one safety-related approach can improve a construction project's safety performance

${ }^{\star}$ Corresponding author. E-mail: hhwei@polyu.edu.hk 
(Li, Lu, Hsu, Gray, \& Huang, 2015; Lu, Cheung, Li, \& Hsu, 2016). Regarding this research gap, the following questions can be raised: Can co-worker safety support significantly improve the safety performance of a construction project? Are there significant differences in improving construction safety performance between different co-workersupport approaches? Answering above questions can help both researchers and practitioners further understand the role of co-worker safety support in workplace safety in the context of construction field.

Therefore, to develop a complete and nuanced understanding of the effects of co-workers' distinct safetysupport actions on construction safety performance, the present study adopts a bottom-up approach called agentbased modeling (ABM): a simulation method allows researchers to use what-if scenarios to investigate how the system-level consequences can emerge from the individual-level interactions (Epstein, 1999). From a perspective of risk theory, an ABM model was created to simulate a construction project - workers reinforce steel bars in a construction site with a crane hazard. Two distinct coworker-support actions - warning co-workers to leave the hazardous area and reminding co-workers to wear personal protective equipment - were individually and jointly implemented in the ABM model to explore their effectiveness on three safety-performance indicators: recordable incident, lost-time incident, and fatal incident. It is hoped that the present methodology can serve as a basis for further studies of the role of co-worker safety support in construction safety, and thus yield practical and theoretical implications for reducing occupational injuries and fatalities among construction workers.

\section{Literature review}

\subsection{Critical factors in construction safety}

In seeking to formulate effective strategies for improving construction safety, researchers have attempted to identify the critical factors that influence safety performance. Some studies have identified such factors by summarizing the opinions of construction-management personnel, and their findings have been decidedly mixed. For example, based on a survey of 120 contractors in the United Kingdom, Sawacha et al. (1999) found that organizations' safety policies have the most dominant influence on their safety performance, among other investigated factors including historical, economic, and procedural factors, etc. After surveying 117 large construction contractors in Egypt, concluded that the most significant factor in companies' safety performance was the safety awareness of their managerial personnel (Abdul-Rashid et al., 2007). Chan (2005) reported that in Hong Kong, the most dominant safety factor was safety communication, but that elsewhere in China, it was safety awareness and training. All of this suggests that construction-safety issues may be culturally specific by nature, making it risky to generalize about such issues based on data from a small number of countries or cities.
A separate body of research has aimed to identify critical construction-safety factors at the project level: usually, via statistical analysis of the relationships between historical safety interventions and the corresponding project's safety performance (represented by lagging indicators such as incidence rate and experience modification rate). Again, the findings have been mixed. For instance, based on an analysis of the 69 safety programs implemented in an individual project in the U.S., Jaselskis et al. (1996) found that the two most significant factors in improving safety performance were the high experience level of the project manager and a supportive safety-management attitude. Hinze et al. (2013) interviewed with managers of 57 construction firms in the U.S. revealed that workerobservation programs and the tracking of injuries that required first aid were the best practices for reducing injury rates. And similar research in Hong Kong evaluated data from 45 construction projects and found that safety training and post-accident investigation were the most effective means of mitigating site casualties (Tam \& Fung, 1998). In short, as well as being somewhat contradictory, almost all the construction-safety factors thus far identified by project-level studies have been restricted to an organizational perspective and have neglected personnel-level factors. This represents a major gap in the literature. Although still limited in number, the discussions of one type of personnel-level factor known as co-worker safety support in the construction-safety field have recently gained prominence, where co-worker safety support was considered as one element of the safety climate of a construction project (Fang, Chen, \& Wong, 2006; Mohamed, 2002).

\subsection{Co-worker safety support}

Co-worker safety support has been defined as a type of social support given by workers to their colleagues in workplaces, focusing on their safety behaviors and performance (McFadden, 2015). Such safety-related assistance offered by colleagues was derived from the concept of Active Caring in Geller's (1991) study, where the authors suggested that "workers could remind their peers not to perform an unsafe act" (p. 607). Co-worker safety support was further defined as a set of explicit approaches in later studies (Burt, Gladstone, \& Grieve, 1998; Mueller, DaSilva, Townsend, \& Tetrick, 1999; Roberts \& Geller, 1996). For example, Burt et al. (1998) designed the Considerate and Responsible Employee Scale with 21 co-worker-support approaches, including "workers should point out hazards to co-workers" and "assist each other with tasks to ensure safety" (p. 365). Based on the findings of these studies, the approaches of co-worker safety support can be categorized into three types: emotion-based, communication-based, and action-based.

Emotion-based safety support aims to enhance the safety awareness of co-workers through giving emotional care, which can involve workers giving positive feedback for working safely, encouraging safe working practices, and reminding one another to adhere to safety guidelines 
(Roberts \& Geller, 1996; S. Tucker, et al., 2008; N. Tucker et al., 2010). Unlike emotional-based support that emphasizes spirit caring, communication-based support is to enhance the safety awareness of co-workers through daily communications among workers, such as regularly scheduled discussions of changes that might prevent accidents and discussions of accidents and near misses that had happened previously (Brondino et al., 2012; Burt et al., 1998). Above two types of support aim to enhance the safety awareness of co-workers by either emotional care or communications, while action-based support emphasizes the specific actions provided by workers to prevent their coworkers from workplace hazards. For example, Roberts and Geller (1996) proposed several actions that could be offered by co-workers in the workplace, including "point out hazards to co-workers" and "warn the co-workers whose behaviors are unsafe". More recently, "remind coworkers to use personal protective equipment" was highlighted in the study of Tucker et al. (2008) as a typical type of action-based support.

In fact, the effects of co-worker safety support on workplace safety have been widely studied in various industries other than construction. According to Watson's et al. (2005) survey of 395 steel-making employees in the Midwestern U.S., co-workers' safety support, including "remind co-workers to work in a safe manner" was indicated to be positively correlated with workers' perceived work environment safety (e.g. perceive the workplace is very safe) and negatively correlated to their at-risk behaviors (e.g. take short-cuts to get the work done). Tucker's et al. (2008) survey of 213 urban bus drivers in U.K. revealed that, in encouraging peers to speak out safety issues in workplace, co-worker support for safety, including "stop co-workers working dangerously," played a more significant role than organizational support for safety (e.g. the company quickly responds to workers' safety concerns). Turner's et al. (2010) survey of 334 U.K. trackside workers indicated that, compared to safety support of senior managers and on-site supervisors, co-workers' safety support, including "remind co-workers to follow safety regulations", was the most significant factor associated with fewer hazardous work events encountered by workers in jobdemanding workplace. Survey by Brondino et al. (2012) of 991 manufacturing workers in Italian discovered that, when it came to enhancing workers' safety compliance and participation, co-worker safety support, including "safety communication and mentoring", had a greater impact than safety supervisors' safety monitoring. More recently, McFadden (2015) survey of 366 trunk drivers in the U.S. showed that team drivers with co-worker safety support conducted more safety behaviors in work (e.g. comply with the posted speed limits) than solo drivers without coworker safety support.

Previous studies have provided abundant empirical evidence on the significant role of co-worker safety support in affecting the safety-related behaviors, attitudes, and perceptions of workers, resulting in the argument of "co-worker safety support can improve workplace safety" in previous studies was restricted in the individual level. It is still unclear that whether co-worker safety support can make a difference to the objective safety outcomes of a project or a company, especially in the construction field, it is often concerned that whether one safety-related approach can improve a construction project's safety performance (Li et al., 2015; Lu et al., 2016). Regarding this research gap, the following questions can be raised: Can co-worker safety support significantly improve the safety performance of a construction project? Are there significant differences in improving construction safety performance between different co-worker-support approaches? Furthermore, researchers have argued that the effectiveness of co-worker safety support may not be as influential in all contexts (Johns, 2006; Rousseau \& Fried, 2001), indicating the necessity of exploring the role of co-worker safety support in workplace safety in the context of the construction industry. The present study's measurement of the impact of co-worker safety support on construction safety performance is therefore an attempt to fill this gap.

\subsection{Agent-based modeling and its application in construction-safety research}

To investigate how individual-level interactions (coworker safety support) emerge system-level consequences (construction safety performance), an agent-based-modeling $(\mathrm{ABM})$ approach is adopted in the present study. Distinguished from statistical-modeling approaches used in above-cited studies, ABM is based on an idea that a real-world system can be modeled using an environment, agents, and a description of agent-agent and agentenvironment interactions (Wilensky, 2015). Specifically, the agents are a collection of autonomous entities with heterogeneous attributes and dynamic behaviors, and the environment is the space constituting of patches where the agents behave and interact (Gilbert \& Terna, 2000). $\mathrm{ABM}$ is especially beneficial in understanding a complex system where the attributes of agents are heterogeneous, the behaviors of agents are adaptive, and the interactions are non-linear and characterized by if-then rules (Bonabeau, 2002). Given that each construction project is a complex system that involves diverse personnel, equipment, and activities, $A B M$ has been seen an effective simulation technique (Sawhney, Bashford, Walsh, \& Mulky, 2003), especially since it takes into account the heterogeneity of construction workers, leading to more meaningful modeling of their interactions (Hsu, Weng, Cui, \& Rand, 2016).

According to the scale of the system investigated, studies using $\mathrm{ABM}$ in the construction safety field can be categorized into three types: task-, project-, and organizationlevel. In task-level studies, various construction tasks were modeled by defining the task-related machines and operators as agents, the construction zone where the machines/ operators performed as the environment, and the operational regulations and safety requirements as interaction rules. Marzouk and Ali (2013), for instance, used ABM to estimate bored-pile productivity while taking account of 
several safety considerations including space availability. In this study, the rig, crane, and pile were defined as distinct types of agents, and the detailed processes of making a bored pile were defined as the interaction rules. More recently, Goh and Ali (2016) proposed a hybrid simulation framework for earthmoving activity, comprising discrete event simulation, system dynamics, and ABM, taking into consideration workers' safety behaviors. It defined trucks, excavators, and operators as agents, and the processes of earthmoving as interaction rules.

In project-level studies, the simulation scale covers the entire construction project with the whole construction site as the environment, on-site personnel (e.g. workers and safety supervisors) and equipment (e.g. crane) as agents, and the overall safety performance of the project being the simulation outcome of their multiple interactions. For instance, to investigate how safety-management policy affected workers' safety behaviors, Walsh and Sawhney (2004) simulated changes in a construction project's processes caused by different safety-management actions and observed how such changes affected construction workers' production and safety records. Lu et al. (2016) investigated how the optimal safety performance could be achieved by different scenarios of safety-investment approaches, including innovative technological tools, employment of safety supervisors, and encouragement of workers to take responsibility for their peers' safety.

Lastly, organization-level studies define various decision-makers as agents and safety communications among the agents as interaction rules. As such, the agents may be several departments of a company, the company itself, or different actors in the construction industry such as contractors, developers, and government. Sharpanskykh and Stroeve (2011) applied ABM to the development of strategies for improving organizational safety culture, by modeling the relationships between such a culture and the organizational structures of air traffic management. To facilitate decision-makers' identification of the optimal strategies for improving their organizations' safety climates, Awwad, Shdid, and Tayeh (2016) modeled safety climate patterns in both bidding and construction phases involving many project stakeholders including contractors, project owners, insurance providers, and government officials. In short, $\mathrm{ABM}$ enables researchers to observe how emergent outcomes vary in response to different scenarios by changing the values of global variables or the versions of the model.

\section{Methodology}

This section introduced how an ABM model was designed as a simulation platform for understanding how distinct co-worker support actions, alone and in combination, affected the safety performance of a construction project. The ABM model was established on NetLogo software, a widely-used ABM language and development environment designed by Wilensky (1999). The proposed model simulated a virtual construction project - workers reinforce steel bars in a construction site with a crane hazard. The virtual construction project was described by defining its project characteristics, the attributes of agents ( $\mathrm{Ta}$ ble A.1 and Table A.3) and environment (Table A.2), the global variables (Table A.4), and the agent-environment and agent-agent interactions. The conceptual framework of methodology is shown in Figure 1. The default values of model variables were set by the data from official statistical reports published by well-known constructionsafety organizations, such as the U.S. Occupational Safety and Health Administration (OSHA), the U.S. Bureau of Labor Statistics (BLS), and 3M Occupational Health and Environmental Safety Division.

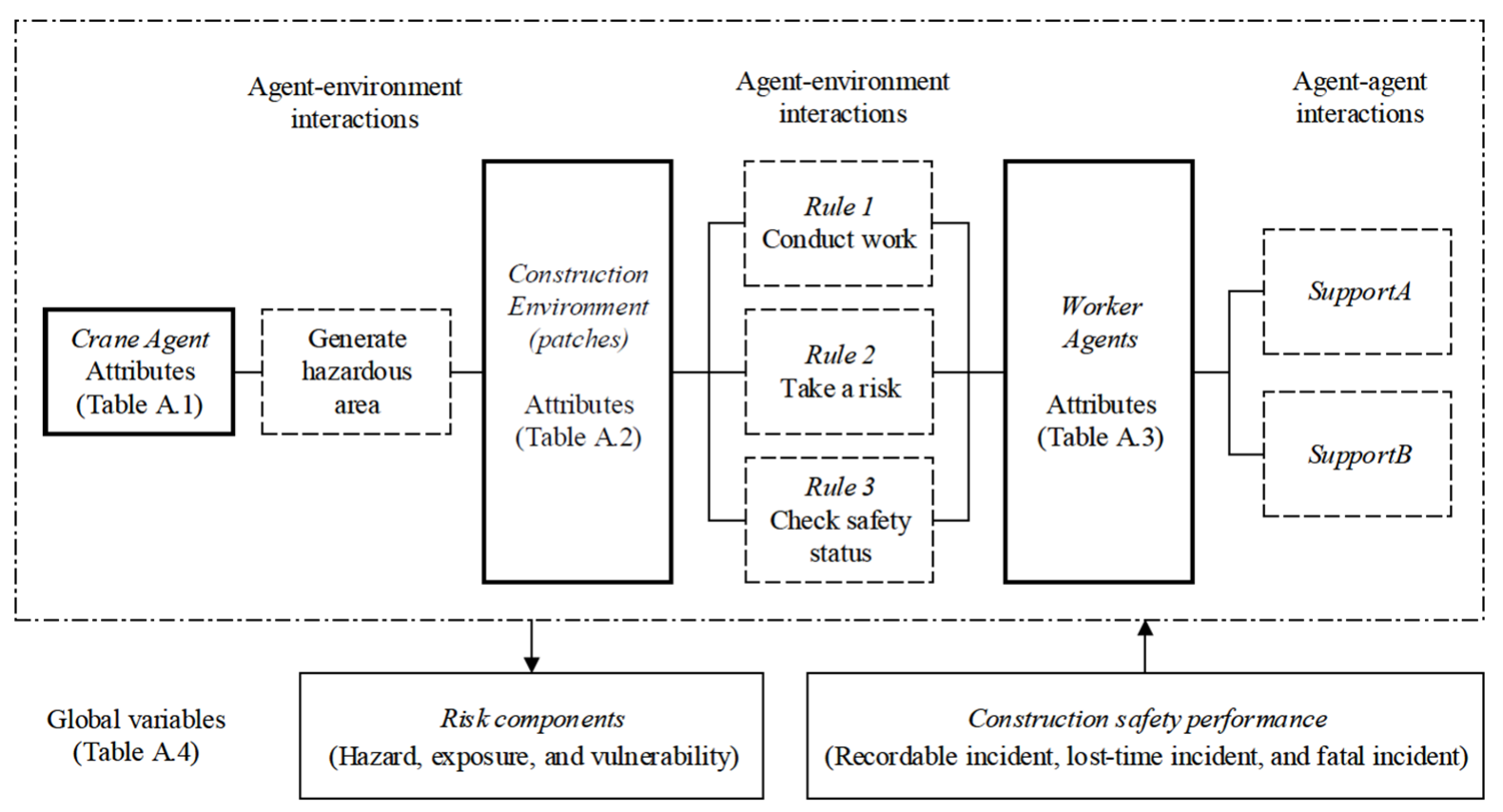

Figure 1. Conceptual framework of methodology 


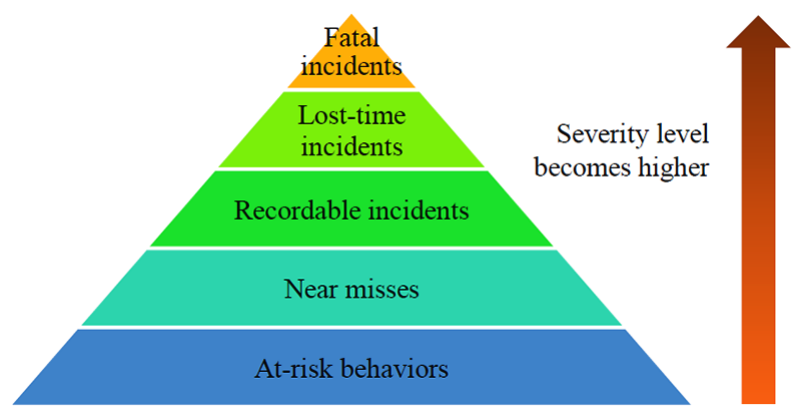

Figure 2. Safety pyramid

\subsection{Safety performance indicators}

To comprehensively measure the safety performance of the virtual construction project, three severity levels of occupational safety indicators required in OSHA regulations were adopted: recordable incident, lost-time incident, and fatal incident (OSHA, 2004). Recordable incident refers to a significant work-related incident in which the involved employee needs medical treatment beyond first aid (Keller, 2018). Lost-time incident is more severe than recordable one, in which the injured employee is unable to return to work for several days (Reyes, 2014). The average days away from work for a lost-time incident is 13 days for the construction sector (BLS, 2016b). Fatal incident is the most severe one among three types of incident, in which the involved employee will be killed in the workplace. The rationality of choosing above three indicators is supported by the model of Safety Pyramid (Figure 2) (adapted from the study of Rebbitt (2014)), demonstrating that recordable incidents, lost-time incidents, and fatal incidents can represent their severity levels in a hierarchical way. It is noteworthy that near misses can also be adopted as one safety-performance indicator in the future work, measuring the occurrence of incidents that not result in an injury but has the potential for an injury exists (Hinze \& Godfrey, 2003).

In the present model, the above three indicators were presented as the global variables recordable-incident, losttime-incident, and fatal-incident. Each worker agent was assigned the attributes individual-recordable-incident and individual-lost-time-incident to record the number of recordable incidents and lost-time incidents suffered during simulation. The global variables recordable-incident and lost-time-incident summarized the individual-recordableincident and the individual-lost-time-incident values of all worker agents, and fatal-incident recorded the number of worker agents that were killed.

\subsection{Environment, agents, and their interactions}

\subsubsection{Basic information and risk theory}

The virtual construction project was created as a 30-storey residential building with floor area of 800 square meters $(32 \times 25 \mathrm{~m})$ with $50 \mathrm{~kg} / \mathrm{sq}$. m of steel bars. Given that ironworkers occupy one of the most hazardous breeds of worker in the construction industry with the highest rate of occupational injuries (Fung, Lo, \& Tung, 2012), the model agents and their working task was defined as ironworkers and steel-bar reinforcement, respectively. According to the labor-production standards for construction work (LD/T74.1-4-2008, 2009), an ironworker can reinforce an average of $400 \mathrm{~kg}$ of steel bars per day, namely 1 sq. $\mathrm{m}$ of steel bars per hour if one works for eight hours per day $(1=400 /(50 \times 8))$. Given the heterogeneity in workers' productivity, each worker agent was assigned with the attribute working-speed with the value following a normal distribution with mean 1 (sq.m/hour) and standard deviation 0.05 .

25 ironworkers were set up to conduct work in the construction site (Figure 3). The time step of simulation was

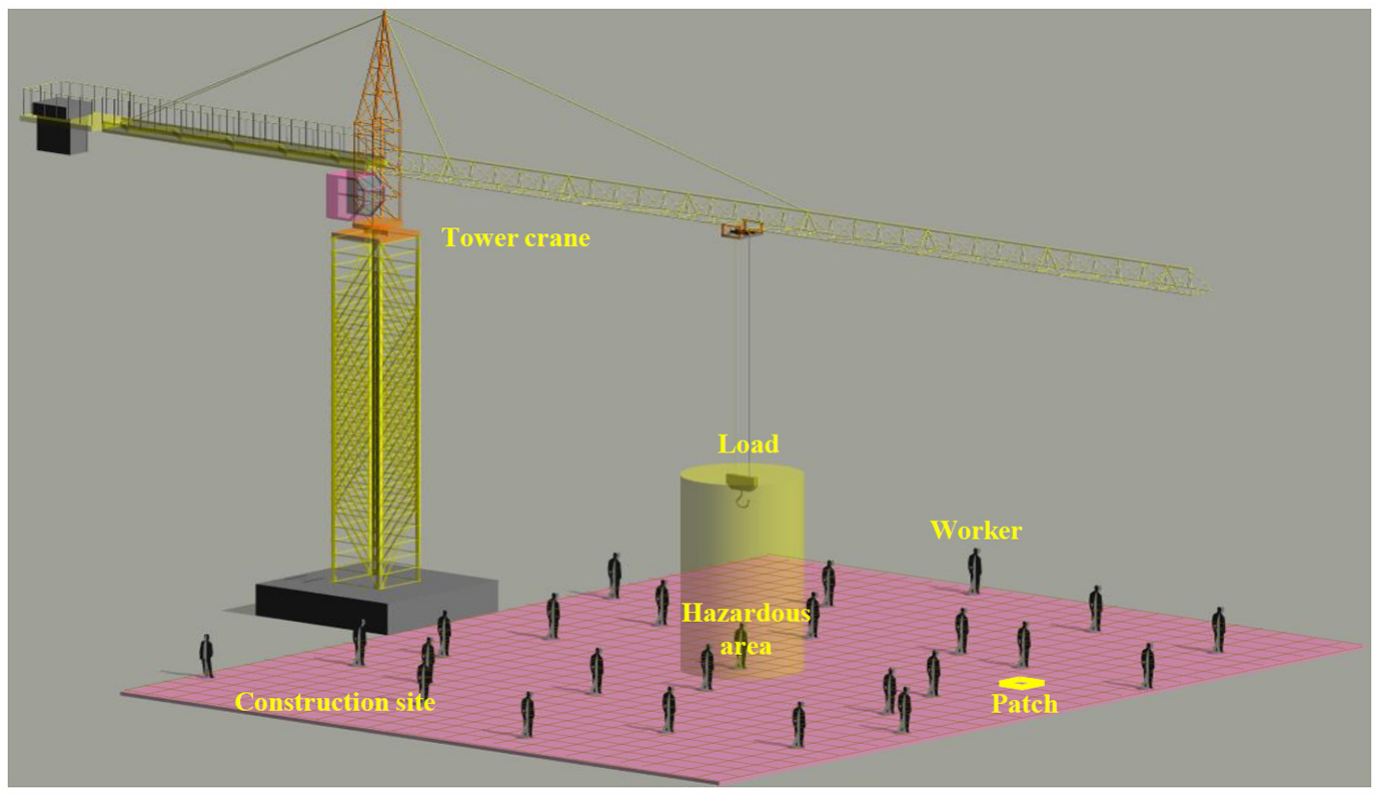

Figure 3. The visualization of the construction site 
set as "one hour per step". In each time step, all workers followed their own working-speed to reinforce steel bar from left side to right side of the construction site. Once finished one floor of the task, the workers continued to conduct the next-floor task until the 30 -storey workloads ( 24000 sq. m of steel bars) were accomplished, and the time steps spent in one-run simulation was recorded as the project construction time (hours).

While conducting work, the worker agents could suffer occupational harm in the construction site. According to the risk theory (UNISDR, 2009), the occupational risk is the likelihood of occurring of an occupational incident, and its consequences result from the interactions between hazard, exposure, and vulnerability (Figure 4). Specifically, the hazard is an external source with a potential for physical harm in terms of injury or fatality, exposure represents the workers in the hazard-prone area that are thereby subject to potential harm, and vulnerability describes the characteristics of a worker that make it susceptible to the negative effects of a hazard. One worker is potential to suffer an occupational harm only when both hazard component and exposure component are overlapped (i.e. one worker is exposed to hazard-prone area), then the severity of such physical harm is determined by the worker's vulnerability (e.g. the worker with high vulnerability is easier to suffer more severe physical harm). As the first principles to build the risk condition of the virtual project, three components of risk: hazard, exposure, and vulnerability, were integrated into the design of ABM model, as described in the following subsections.

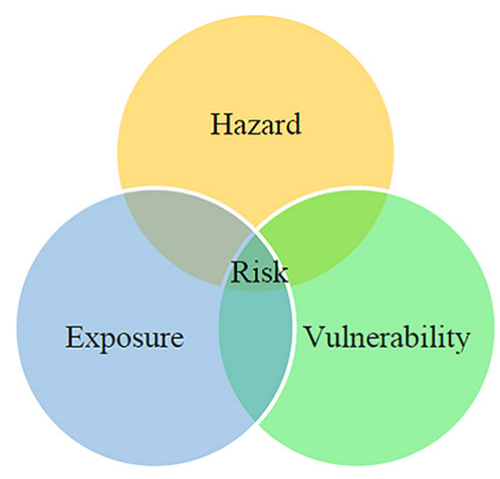

Figure 4. Three components of risk

\subsubsection{Hazard component}

Though many different hazards exist on real construction sites, the present model designated only a tower-crane agent as the external hazard source with the danger of dropping the load. This is justified, insofar as more fatal accidents in the construction industry are related to cranes than to any other type of equipment. In addition, the load on the crane jib (e.g. steel bars) is relatively fixed and easy to notice, and therefore a reasonable topic of co-workers' safety reminders. As illustrated in Figure 5, in each time step the crane agent could generate a circle-shaped hazardous area (the projection of a cylinder) (Li et al., 2015)



Figure 5. The illustration of the hazardous area

with the radius of $1 \mathrm{~m}$. The size of the hazardous area is appropriate for the present construction project given factors such as workplace conditions, load size and weight, and lifting height (10/2011-1-COP27, 2011). The precise location of the hazardous area was randomly changeable due to the crane's ever-changing attributes: i.e. the length of crane jib ranges (length) from $5 \mathrm{~m}$ to $30 \mathrm{~m}$ and its heading (heading) from $-90^{\circ}$ to $90^{\circ}$ (Table A.1).

However, because of uncertain casual factors (e.g. overloading, the failure of crane operations, or broken jib), the load dropped from the crane was potential to fall on any one of patches inside the hazardous area (the size of one patch is one square meter). Each patch of the construction site was assigned with the attribute danger with default value 0 , meaning that workers were safe to conduct work here. Once a dropped-load event happened, the danger of the patch on which the load dropped would turn into 1, while the danger of other patches inside hazardous area remained 0 for not being hit by the fallen load. To describe the probability of the dropped-load event, the global variable hazard-level was introduced in the model display ranging from 0 to 50 in increment of 1 . Hazardlevel 0 represents the construction site is totally safe - no dropped-load incident happens in the construction site, while 50 represents extremely danger - 100 percent of probability occurring the dropped-load event. As such, the value of hazard-level describes the level of hazard component, which is adjustable for the interest of model players.

\subsubsection{Exposure component}

Many occupational-accident reports concluded that 20\% of accidents were caused by unsafe conditions, and $80 \%$ by unsafe behaviors (DuPont, 1983; Heinrich, 1959; Krause, 1997). If the external hazard source (i.e. crane tower) is the unsafe condition making the workers potentially harmed, then conducting work in the hazardous area intentionally is the unsafe behavior increasing their exposure to 
hazard. A large body of behavior-based-safety literature has demonstrated that workers' safety awareness predicts their likelihoods of taking unsafe behaviors in the workplace, specifically, the workers with lower safety awareness are more likely to conduct unsafe behaviors (Chen, McCabe, \& Hyatt, 2018; Choudhry \& Fang, 2008; Man, Chan, \& Wong, 2017). To describe their likelihood of walking into the hazardous area, worker agents were assigned the attribute safety-awareness ranging from $0(100$ percent of probability walking into the hazardous area) to 100 (0 percent of probability).

In each time step, worker agents would determine whether to take a risk to conduct work in the dangerous area head of them. A random number $(0-100)$ was generated by the model to compare with the value of safetyawareness of each worker agent. If the generated random number was smaller than the safety-awareness of one worker, he would avoid walking inside the front hazardous area; otherwise, he would take the risk to walk in. Given the heterogeneity in workers' safety awareness, the value of safety-awareness could randomly fall within a normal distribution with mean (mean.SA) and standard deviation 5. The value of mean.SA described the level of exposure component, which was adjustable for the interest of model players.

The default values of hazard-level and mean.SA were then set to a level of construction-industry average. According to the occupational-injury census data published by the U.S. Bureau of Labor Statistics, the average number of recordable injuries in a construction project was 23 injuries per 1000 full-time equivalent workers (BLS, 2014), namely around 0.6 injuries per 25 workers for the present model, among which $0.12(0.6 \times 20 \%)$ was expected to be caused by only unsafe conditions. Given that even all workers are unintentionally to conduct unsafe behaviors, there is still a small-probability (5\%) case that the workers can be accidentally exposed to the hazard-prone area (Milazzo, Spasojević-Brkić, \& Ancione, 2015). Base on above official data, an average of $0.12(0.6 \times 20 \%)$ injuries are expected to be caused by unsafe conditions when the workers have $5 \%$ of probability (i.e. small probability (BMJ, 2018)) being exposed to hazard (i.e. safety-awareness $=95$ ). The results of 5000-run simulations showed that, in the case of safety-awareness 95, the recordable-incident could stay around 0.12 when hazard-level was set as 5 ; in the case of hazardlevel 5, the recordable-incident could reach to around 0.6 when mean.SA was set as 75 (Table 1). To sum up, when the default values of hazard-level and mean.SA were set

Table 1. Results for determining the default value of hazard-level and mean.SA

\begin{tabular}{|c|c|c|c|}
\hline \multirow{2}{*}{ Hazard-level } & \multirow{2}{*}{ Mean.SA } & \multicolumn{2}{|c|}{ Recordable incident } \\
\cline { 3 - 4 } & & Mean & SD \\
\hline 5 & 95 & 0.118 & 0.345 \\
\hline 5 & 75 & 0.605 & 0.784 \\
\hline
\end{tabular}

as 5 and 75 respectively, the level of hazard and exposure component could achieve the construction-industry average.

\subsubsection{Vulnerability component}

After whether a worker works in a dangerous patch was determined, his safety status was then checked by the model in each time step: a worker would get injured if standing on the patch with danger 1 or be safe if with danger 0 . Such an incident would be assigned to one of three severity levels: (1) a recordable incident, after which the attribute individual-recordable-incident associated with this worker would be increased by one; (2) a lost-time incident, upon which the attribute individual-lost-time incident increased by one; meanwhile, the worker would also spend 13 days (104 hours) away from work; (3) a fatal incident, after which the worker would die, and the global variable fatal-incident would be increased by one. Once one worker was killed, and the virtual construction project would not recruit a new worker.

The relative likelihood of each type of incident was based on the occupational-injury census data provided by the U.S. Bureau of Labor Statistics: i.e., that a lost-time incident was $35 \%$ as likely as a recordable incident, and a fatal incident $0.26 \%$ as likely as a recordable incident (BLS, 2017). However, workers with high vulnerability to hazard are more likely to suffer severe injuries, e.g. workers not wearing personal protective equipment (PPE) are more likely to suffer lost-time injuries or fatality than workers wearing PPE. PPE refers to the equipment worn by workers to protect them against physical harm caused by external hazard (Farooqui, Ahmed, Panthi, \& Azhar, 2009). It was reported that workers without PPE protection were nearly 5 times more likely to suffer lost-time injuries than ones with PPE protection (UMSL, 2014), and 9 times for fatal injuries (Ho, 2016). Based on above official data, for worker agents without PPE protection, the physical harm they suffered was deemed to be a lost-time incident $(35 \% \times 5>1)$ and had $2.34 \%(0.26 \% \times 9)$ of probability turning into a fatal incident. To describe their PPE-wearing status, worker agents were assigned the attribute PPE-status with the value 0 (without PPE) or 1 (with PPE). The number of workers not wearing PPE was determined by the global variable Num-NoPPE ranging from 0 to 25 in increment of 1 . According to the survey data provided by the $3 \mathrm{M}$ Occupational Health and Environmental Safety Division, around $80 \%$ of construction workers admitted to always wear PPE on work (Randles, 2009); therefore, the default value of Num-NoPPE was set as $5(25 \times 20 \%)$ to achieve the level of construction-industry average. The value of Num-NoPPE described the level of vulnerability component, which was adjustable by the interest of model players.

\subsection{Interactions among agents}

The interactions among the agents in the present model were represented as the safety support provided by coworkers. From the perspective of risk theory, occupational 
risk can be reduced by three approaches: reduce hazard, reduce exposure, and reduce vulnerability. Given that the dropped-load hazard is impossible to be reduced by coworker support, only two distinct action-based co-workersupport approaches were introduced in the present model: 1) SupportA: warn co-workers to leave hazardous area (Burt et al., 1998; Roberts \& Geller, 1996; Watson et al., 2005) - aiming to reduce exposure, and 2) SupportB: remind co-workers to wear Personal Protective Equipment (PPE) (Brondino et al., 2012; Tucker et al., 2008) - aiming to reduce vulnerability. Global variables SupportA and SupportB were assigned to control whether to activate the respective co-worker-support action.

At each time step, if the global variable SupportA was activated, one worker would be reminded to leave the hazardous area if he was seen by co-workers in a safe area; if the global variable SupportB was activated, one worker would be reminded to wear PPE if he was seen by coworkers wearing PPE. One worker behaving unsafely (e.g. PPE-status $=0$ ) could be seen by other workers only when he was within the visual range of his co-workers behaving safely (e.g. PPE-status = 1) - no more than five meters away and within $60^{\circ}$ of the direct line of sight (Rayner,
1975). However, the influence of this support mechanism on the warned workers only lasted for one time-step, with all reverting to their normal unsafe behaviors in the following step.

\section{Simulation results}

To investigate the effectiveness of two distinct co-workersupport actions on construction safety performance in three levels (i.e., recordable incident, lost-time incident, and fatal incident), four types of co-worker-support scenarios were implemented on the proposed ABM model: 1) SP0: neither SupportA nor SupportB was activated (control group as a baseline measure); 2) SPA: only SupportA was activated 3) SPB: only SupportB was activated, and 4) SPAB: both SupportA and SupportB were activated. The risk condition was set to the construction-industry average, i.e. the global variables hazard-level, mean.SA, and Num.NoPPE remained the default values 5, 75, and 5, respectively. For each co-worker-support scenario, 5,000 runs of simulation were conducted to generate 20,000 samples of data for the analysis. Table 2 shows the simulation results in different co-worker-support scenarios. By

Table 2. The occurrence of different number of incidents in three levels by co-worker-support scenario

\begin{tabular}{|c|c|c|c|c|c|c|}
\hline \multirow{2}{*}{ Indicator } & \multirow{2}{*}{ Number of incidents } & \multirow{2}{*}{ Occurrence } & \multicolumn{4}{|c|}{ Co-worker-support scenario } \\
\hline & & & SP0 & SPA & SPB & SPAB \\
\hline \multirow[t]{12}{*}{ Recordable incident } & \multirow[t]{2}{*}{0} & Frequency & 2730 & 3067 & 2773 & 3192 \\
\hline & & Probability (\%) & $54.6 \%$ & $61.3 \%$ & $55.5 \%$ & $63.8 \%$ \\
\hline & \multirow[t]{2}{*}{1} & Frequency & 1690 & 1548 & 1642 & 1365 \\
\hline & & Probability (\%) & $33.8 \%$ & $31.0 \%$ & $32.8 \%$ & $27.3 \%$ \\
\hline & \multirow[t]{2}{*}{2} & Frequency & 467 & 337 & 468 & 372 \\
\hline & & Probability (\%) & $9.3 \%$ & $6.7 \%$ & $9.4 \%$ & $7.4 \%$ \\
\hline & \multirow[t]{2}{*}{3} & Frequency & 99 & 41 & 107 & 60 \\
\hline & & Probability (\%) & $2.0 \%$ & $0.8 \%$ & $2.1 \%$ & $1.2 \%$ \\
\hline & \multirow[t]{2}{*}{4} & Frequency & 12 & 6 & 8 & 10 \\
\hline & & Probability (\%) & $0.2 \%$ & $0.1 \%$ & $0.2 \%$ & $0.2 \%$ \\
\hline & \multirow[t]{2}{*}{5} & Frequency & 2 & 1 & 2 & 1 \\
\hline & & Probability (\%) & $0.0 \%$ & $0.0 \%$ & $0.0 \%$ & $0.0 \%$ \\
\hline \multirow[t]{8}{*}{ Lost-time incident } & \multirow[t]{2}{*}{0} & Frequency & 4325 & 4497 & 4508 & 4533 \\
\hline & & Probability (\%) & $86.5 \%$ & $89.9 \%$ & $90.2 \%$ & $90.7 \%$ \\
\hline & \multirow[t]{2}{*}{1} & Frequency & 632 & 484 & 471 & 440 \\
\hline & & Probability (\%) & $12.6 \%$ & $9.7 \%$ & $9.4 \%$ & $8.8 \%$ \\
\hline & \multirow[t]{2}{*}{2} & Frequency & 41 & 19 & 20 & 26 \\
\hline & & Probability (\%) & $0.8 \%$ & $0.4 \%$ & $0.4 \%$ & $0.5 \%$ \\
\hline & \multirow[t]{2}{*}{3} & Frequency & 2 & 0 & 1 & 1 \\
\hline & & Probability (\%) & $0.0 \%$ & $0.0 \%$ & $0.0 \%$ & $0.0 \%$ \\
\hline \multirow[t]{4}{*}{ Fatal incident } & \multirow[t]{2}{*}{0} & Frequency & 4974 & 4984 & 4985 & 4988 \\
\hline & & Probability (\%) & $99.5 \%$ & $99.7 \%$ & $99.7 \%$ & $99.8 \%$ \\
\hline & \multirow[t]{2}{*}{1} & Frequency & 26 & 16 & 15 & 12 \\
\hline & & Probability (\%) & $0.5 \%$ & $0.3 \%$ & $0.3 \%$ & $0.2 \%$ \\
\hline
\end{tabular}


using the " $R$ " program, the simulation data were further analyzed by the Chi-square test for independence to investigate whether the occurrence of three types of incidents can be significantly reduced after imposing three co-worker-support treatments (i.e. SPA, SPB, and SPAB) when compared to the control group (i.e. SP0), and whether there are significant differences in reducing three types of incidents between three co-worker-support treatments. Table 3 shows the results of Chi-square test for the simulation data. The differences between four scenarios were considered significant when the probability of error was less than or equal to $0.05(\alpha=0.05)$.

With the activation of SPA, the occurrence of recordable incident $\left(\chi^{2}=46, P=0.000\right)$ and lost-time incident $\left(\chi^{2}=28, P=0.000\right)$ was significantly reduced compared to SP0. The probability of no recordable incident and losttime incident, occurred in the virtual project increased from $54.6 \%$ to $61.3 \%$, and $86.5 \%$ to $89.9 \%$, respectively. However, although the probability of occurring fatal incident was reduced after $(0.3 \%)$ the activation of SPA than before $(0.5 \%)$, the result of Chi-square test showed that such positive effect was not significant $\left(\chi^{2}=1.9, P=0.2\right)$.

With the activation of SPB, the occurrence of lost-time incident was significantly reduced $\left(\chi^{2}=32, P=0.000\right)$, compared to SPO. The probability of no lost-time incident occurred in the virtual project could increase to nearly

Table 3. Chi-square test for comparing the independence between co-worker-support scenario and the occurrence of zero incident in three levels

\begin{tabular}{|c|c|c|c|c|}
\hline Indicator & $\begin{array}{c}\text { Co-worker- } \\
\text { support } \\
\text { scenario }\end{array}$ & $\begin{array}{c}\text { Co-worker- } \\
\text { support } \\
\text { scenario }\end{array}$ & $\chi_{0.05,4}^{2}$ & $\mathrm{P}$-value \\
\hline \multirow{6}{*}{$\begin{array}{l}\text { Recordable } \\
\text { incident }\end{array}$} & SPA & SP0 & 46 & $0.000^{* * *}$ \\
\hline & SPB & SP0 & 0.71 & 0.400 \\
\hline & SPAB & SP0 & 88 & $0.000^{* * *}$ \\
\hline & SPB & SPA & 35 & $0.000^{\star * *}$ \\
\hline & SPAB & SPA & 6.6 & $0.010^{\star *}$ \\
\hline & SPAB & SPB & 73 & $0.000^{\star * *}$ \\
\hline \multirow{6}{*}{$\begin{array}{l}\text { Lost-time } \\
\text { incident }\end{array}$} & SPA & SP0 & 28 & $0.000^{* * *}$ \\
\hline & SPB & SP0 & 32 & $0.000^{\star * *}$ \\
\hline & SPAB & SP0 & 42 & $0.000^{* * *}$ \\
\hline & SPB & SPA & 0.11 & 0.700 \\
\hline & SPAB & SPA & 1.4 & 0.200 \\
\hline & SPAB & SPB & 0.66 & 0.400 \\
\hline \multirow{6}{*}{$\begin{array}{l}\text { Fatal } \\
\text { incident }\end{array}$} & SPA & SP0 & 1.9 & 0.200 \\
\hline & SPB & SP0 & 2.4 & 0.100 \\
\hline & SPAB & SP0 & 4.5 & $0.030^{*}$ \\
\hline & SPB & SPA & 0 & 1.000 \\
\hline & SPAB & SPA & 0.32 & 0.600 \\
\hline & SPAB & SPB & 0.15 & 0.700 \\
\hline
\end{tabular}

Note: '***) means P-value $\leq 0.001$; ${ }^{(* *)}$ means P-value $\leq 0.01$;

'*' means P-value $\leq 0.05$. ninety percent $(90.2 \%)$, which was $3.4 \%$ higher than nosupport scenario (86.5\%). However, there was no significant difference in reducing the frequency of lost-time incident between SPB and SPA $\left(\chi^{2}=0.11, P=0.7\right)$, indicating that the effectiveness of SupportB and SupportA on reducing lost-time incident was the nearly same. The positive effect of SupportB was also insignificant on reducing the occurrence of fatal incident $\left(\chi^{2}=2.4, P=0.1\right)$.

With the activation of SPAB, the occurrence of recordable incident was significantly reduced $\left(\chi^{2}=88, P=0.000\right)$, with $63.8 \%$ of probability of no recordable incident happened, compared to SP0. Although the effectiveness of SPAB shown in percentage was only $2.5 \%$ higher than SPA, the difference in reducing the frequency of recordable incident between SPAB and SPA was significant $\left(\chi^{2}=6.6, P=0.01\right)$. Regarding reducing the occurrence of lost-time incident, compared to SP0, the effectiveness of SPAB was proved to be significant $\left(\chi^{2}=42, P=0.000\right)$, representing in the probability of the occurrence of lost-time incident was reduced by $9.3 \%$ from $100 \%$ to $90.7 \%$; however, such effect showed no difference when compared with SPA $\left(\chi^{2}=1.4, P=0.2\right)$ and SPB $\left(\chi^{2}=0.66, P=0.400\right)$. It was surprising to find that, the probability of the occurrence of fatal incident cannot be significantly reduced by merely single co-worker-support action (SPA or SPB) but can be significantly reduced by combined co-worker-support actions $(\mathrm{SPAB})\left(\chi^{2}=4.5, P=0.03\right)$.

\section{Discussion and conclusions}

The present study aims to investigate the effects of two distinct co-worker-support actions on three severity levels of safety performance of a construction project. The simulation results indicate that the combined co-worker-support action can be effective in reducing three severity levels of incidents, whereas a single co-worker-support action is only effective in reducing nonfatal incident but ineffective in reducing fatal incident. Specifically, the occurrence of recordable incident can be significantly reduced in a construction project where workers remind each other to leave the hazardous area; the occurrence of lost-time incident can be significantly reduced when workers remind their peers to leave the hazardous area or wear PPE. However, the occurrence of fatal incident could only be significantly reduced in a situation where both workers remind each other leave hazardous area and wear PPE. It could be partly explained by the fact that, for a construction project with an industry-average level of risk condition, the probability of occurring fatal incident is too small $(0.5 \%)$ to be improved. This finding implies the necessity of introducing multiple types of co-worker support approaches in real-world practice if a construction project aims to achieve an all-round safety-performance improvement. In addition, this finding also adds further support to Turner's et al. (2010) study who found the potential role of co-worker support in reducing the occurrence of occupational injuries. 
The results also suggest that, in reducing the occurrence of high-severity incidents (i.e. lost-time incident and fatal incidents), the action of warning peers to leave the hazardous area has the same effectiveness as the one of reminding peers to wear PPE. To be specific, both actions are the same effective in reducing the occurrence of lost-time incidents and similarly, show little influence on fatal incidents. This finding highlights the advantages of warning peers to leave the hazardous area in improving construction safety performance: not only it has the capability for reducing the occurrence of recordable incidents but also shows the same effectiveness as the action of reminding peers to wear PPE in reducing lost-time incidents. This finding can be also supported by the idea of Hierarchy of Health and Safety Controls that has been widely accepted by numerous safety organizations: if a hazard cannot be eliminated or substituted, the next best way is to provide warning systems to reduce the time the workers are exposed to hazard, while PPE protection is the least effective method and should be the last resort to protect workers from a hazard (Manuele, 2005; NIOSH, 2018; UAW, 2001). Based on the above findings, decision makers in the construction field (e.g. contractors, project managers, and safety managers) are suggested to publicize the notion of "co-worker support for safety" through safety education and training, especially emphasize on the co-worker-support actions that are capable to reduce co-workers' exposure to the on-site hazards but not limited in cranes, such as trucks, excavators, holes in slabs, and so forth.

These findings help to disentangle how objective safety outcomes of a construction project may be influenced by the safety-related assistance among workers. The present study is the first to our knowledge to translate the locallevel effects of interactions among individual workers into the system-level consequences of a construction project, namely how different levels of safety performance indicators are potential to be enhanced through the action-based co-worker support approaches. Past empirical research has mainly examined how the behaviors of individual workers are correlated with their perceived co-worker safety support, rather than linking the relationship between coworker safety support and the whole safety performance of the workplace. Anchoring the present study in a risk theory provides a theoretical lens for better understanding the effectiveness of two distinct action-based co-worker support approaches on construction safety. Previous studies have mainly investigated the positive effect of the safety-related support of co-workers with comparison with the one of supervisors or organizations from a perspective of social capital theory, rather than in-depth differentiating the effectiveness of distinct approaches of co-worker safety support on workplace safety from a perspective of risk theory.

Nevertheless, the findings of the present study are only applicable to most construction projects with an average risk level. For those projects with high-risk level, it is uncertain that whether the effects of different co-worker- support approaches on construction safety performance are more significant or not. In a high-risk workplace, one worker is more likely to be harmed by hazards for their at-risk behaviors (1e.g. walk in the hazardous area). In this regard, the probability will increase for co-worker-support approaches to help workers escape from danger, but meanwhile, there are less qualified workers (workers without at-risk behaviors) enable to provide safety-related assistance to their co-workers with at-risk behaviors. As such, the interested researchers can change the values of three global variables in the ABM model (hazard-level, mean.SA, and Num-NoPPE) to further investigate how the effects of different co-worker-support approaches on construction safety performance can react in a high-risk construction project.

Despite the advantages of co-worker safety support, the influence of co-worker has been argued not always be positive (Bruk-Lee \& Spector, 2006; Chiaburu \& Harrison, 2008). In the opposite of support, co-workers may provide wrong safety-related signals to other employees to interrupt their works (one form of co-worker antagonism), which has been proved to be negatively related with workers' working performance (Chiaburu \& Harrison, 2008). Such influence mechanism can be introduced to the present $A B M$ model to further discuss the effect of co-worker support on both safety and productivity performance of a construction project.

The present study is subject to some limitations. First, although most parameters in the present $\mathrm{ABM}$ model were set based on the empirical data from the official documents, there are still some free parameters (e.g. the initial number of worker agents) set based on anecdotal experience in the construction field. It is justified because an appropriate level of model simplification and empirical realism is important while an accurate representation of all the details of a construction project is not (Axelrod, 1997; Epstein, 1999). Those free parameters can be further varied to explore model behavior or calibrated by empirical data from future research (Eberlen, Scholz, \& Gagliolo, 2017). Second, the behaviors of agents in the present ABM model were reactive to the stimuli but not adaptive to it in the light of their experience, to be specific, the worker agents could react to the reminders from other co-workers but could not modify their unsafe behaviors regardless of how many times they had been reminded. As such, it may underestimate the effectiveness of co-worker safety support, and future researchers can usefully introduce learning theory into the construction of agents in the ABM model. In conclusion, by using an agent-based-modeling approach, the present study extends our existing body of knowledge on the significant role of co-worker safety support to workplace safety in the context of the construction field. More studies are encouraged to use ABM method to in-depth investigate the effect of a wider variety of co-workers' safetyrelated assistance (including communication-based and emotion-based one) on the construction safety. 


\section{References}

10/2011-1-COP27: Code of practice for safe use of tower cranes. (2011). The Occupational Safety and Health Branch, Labour Department, Hong Kong.

Abdul-Rashid, I., Bassioni, H., \& Bawazeer, F. (2007). Factors affecting safety performance in large construction contractors in Egypt. In Proceedings of the $23^{\text {rd }}$ Conference of Association of Researchers in Construction Management (pp. 661-670). Belfast, Northern Ireland.

Awwad, R., Shdid, C. A., \& Tayeh, R. (2016). Agent-based model for simulating construction safety climate in a market environment. Journal of Computing in Civil Engineering, 31(1), 05016003.

https://doi.org/10.1061/(ASCE)CP.1943-5487.0000612

Axelrod, R. (1997). Advancing the art of simulation in the social sciences. In Proceedings of the Simulating Social Phenomena. Lecture Notes in Economics and Mathematical Systems (pp. 2140). Berlin, Heidelberg. https://doi.org/10.1007/978-3-662-03366-1_2

BLS. (2014). Incidence rate and number of nonfatal occupational injuries by industry and ownership, 2014. Retrieved from https://www.bls.gov/iif/oshwc/osh/os/ostb4351.pdf

BLS. (2016a). Census of fatal occupational injuries, 2015. Retrieved from https://www.bls.gov/iif/oshwc/cfoi/cfch0014.pdf

BLS. (2016b). Nonfatal occupational injuries and illnesses requiring days away from work, 2015. Retrieved from https://www.bls.gov/news.release/pdf/osh2.pdf

BLS. (2017). Schedule of upcoming releases and access to archived news releases. Retrieved from https://www.bls.gov/iif/osh_ nwrl.htm

BMJ. (2018). Statements of probability and confidence intervals. Retrieved from https://www.bmj.com/about-bmj/resourcesreaders/publications/statistics-square-one/4-statements-probability-and-confiden

Bonabeau, E. (2002). Agent-based modeling: Methods and techniques for simulating human systems. Proceedings of the $\mathrm{Na}$ tional Academy of Sciences (PNAS), 99(Suppl 3), 7280-7287. https://doi.org/10.1073/pnas.082080899

Brondino, M., Silva, S. A., \& Pasini, M. (2012). Multilevel approach to organizational and group safety climate and safety performance: Co-workers as the missing link. Safety Science, 50(9), 1847-1856. https://doi.org/10.1016/j.ssci.2012.04.010

Bruk-Lee, V., \& Spector, P. E. (2006). The social stressors-counterproductive work behaviors link: Are conflicts with supervisors and coworkers the same?. Journal of Occupational Health Psychology, 11(2), 145-156. https://doi.org/10.1037/1076-8998.11.2.145

Burt, C. D., Gladstone, K. L., \& Grieve, K. R. (1998). Development of the Considerate and Responsible Employee (CARE) scale. Work \& Stress, 12(4), 362-369.

https://doi.org/10.1080/02678379808256873

Chan, A. P. C. (2005). From attitude to culture: Effect of safety climate on construction safety. The Hong Kong Polytechnic University, Department of Building and Real Estate, Hong Kong.

Chen, Y., McCabe, B., \& Hyatt, D. (2018). A resilience safety climate model predicting construction safety performance. Safety Science, 109, 434-445.

https://doi.org/10.1016/j.ssci.2018.07.003

Cheng, E. W., Ryan, N., \& Kelly, S. (2012). Exploring the perceived influence of safety management practices on project performance in the construction industry. Safety Science, 50(2), 363 369. https://doi.org/10.1016/j.ssci.2011.09.016
Chiaburu, D. S., \& Harrison, D. A. (2008). Do peers make the place? Conceptual synthesis and meta-analysis of coworker effects on perceptions, attitudes, OCBs, and performance. Journal of Applied Psychology, 93(5), 1082-1103. https://doi.org/10.1037/0021-9010.93.5.1082

Choudhry, R. M., \& Fang, D. (2008). Why operatives engage in unsafe work behavior: Investigating factors on construction sites. Safety Science, 46(4), 566-584. https://doi.org/10.1016/j.ssci.2007.06.027

DuPont, E. I. (1983). Results of ten year DuPont study. Safety Training Observation Program. Wilmington, Delaware.

Eberlen, J., Scholz, G., \& Gagliolo, M. (2017). Simulate this! An introduction to agent-based models and their power to improve your research practice. International Review of Social Psychology, 30(1), 149-160. https://doi.org/10.5334/irsp.115

Epstein, J. M. 1999. Agent-based computational models and generative social science. Complexity, 4(5), 41-60. https://doi.org/10.1002/(SICI)10990526(199905/06)4:5<41::AID-CPLX9>3.0.CO;2-F

Fang, D., Chen, Y., \& Wong, L. (2006). Safety climate in construction industry: A case study in Hong Kong. Journal of Construction Engineering and Management, 132(6), 573-584. https://doi.org/10.1061/(ASCE)0733-9364(2006)132:6(573)

Farooqui, R. U., Ahmed, S. M., Panthi, K., \& Azhar, S. (2009). Addressing the issue of compliance with personal protective equipment on construction worksites: A workers' perspective. Retrieved from http://ascpro0.ascweb.org/archives/cd/2009/ paper/CPRT176002009.pdf

Fung, I. W., Lo, T. Y., \& Tung, K. C. (2012). Towards a better reliability of risk assessment: Development of a qualitative \& quantitative risk evaluation model $\left(\mathrm{Q}^{2} \mathrm{REM}\right)$ for different trades of construction works in Hong Kong. Accident Analysis \& Prevention, 48, 167-184. https://doi.org/10.1016/j.aap.2011.05.011

Geller, E. S. (1991). If only more would actively care. Journal of Applied Behavior Analysis, 24, 607-612.

Gilbert, N., \& Terna, P. (2000). How to build and use agent-based models in social science. Mind \& Society, 1(1), 57-72. https://doi.org/10.1007/BF02512229

Goh, Y. M., \& Ali, M. J. A. (2016). A hybrid simulation approach for integrating safety behavior into construction planning: An earthmoving case study. Accident Analysis \& Prevention, 93, 310-318. https://doi.org/10.1016/j.aap.2015.09.015

Heinrich, H. W. (1959). Industrial accident prevention: A scientific approach ( $4^{\text {th }}$ ed.). New York: McGraw-Hill.

Hinze, J., \& Godfrey, R. (2003). An evaluation of safety performance measures for construction projects. Journal of Construction Research, 4(1), 5-15. https://doi.org/10.1142/S160994510300025X

Hinze, J., Hallowell, M., \& Baud, K. (2013). Construction-safety best practices and relationships to safety performance. Journal of Construction Engineering and Management, 139(10), 04013006 . https://doi.org/10.1061/(ASCE)CO.1943-7862.0000751

Ho, O. (2016). Nine in 10 construction deaths due to workers overlooking safety: Manpower Minister. Retrieved from https://www.straitstimes.com/singapore/manpower/nine-in10-construction-deaths-due-to-workers-overlooking-safetymanpower

Hsu, S.-C., Weng, K.-W., Cui, Q., \& Rand, W. (2016). Understanding the complexity of project team member selection through agent-based modeling. International Journal of Project Management, 34(1), 82-93. https://doi.org/10.1016/j.ijproman.2015.10.001 
Jannadi, O. A., \& Bu-Khamsin, M. S. (2002). Safety factors considered by industrial contractors in Saudi Arabia. Building and Environment, 37(5), 539-547.

https://doi.org/10.1016/S0360-1323(01)00056-7

Jaselskis, E. J., Anderson, S. D., \& Russell, J. S. (1996). Strategies for achieving excellence in construction safety performance. Journal of Construction Engineering and Management, 122(1), 6170. https://doi.org/10.1061/(ASCE)0733-9364(1996)122:1(61)

Johns, G. (2006). The essential impact of context on organizational behavior. Academy of Management Review, 31(2), 386408. https://doi.org/10.5465/amr.2006.20208687

Keller, J. J. (2018). Guide to OSHA recordable injuries and illnesses. Retrieved from https://www.jjkeller.com/learn/guide-to-OSHA-recordable-injuries-and-illnesses

Krause, T. R. (1997). The behavior-based safety process: Managing involvement for an injury-free culture ( $2^{\text {nd }}$ ed.). New York: Van Nostrand Reinhold Company.

LD/T74.1-4-2008: The labor production standards for construction works (1 ed.). (2009). China Planning Press, Beijing.

Li, H., Lu, M., Hsu, S.-C., Gray, M., \& Huang, T. (2015). Proactive behavior-based safety management for construction safety improvement. Safety Science, 75, 107-117.

https://doi.org/10.1016/j.ssci.2015.01.013

Lu, M., Cheung, C. M., Li, H., \& Hsu, S.-C. (2016). Understanding the relationship between safety investment and safety performance of construction projects through agent-based modeling. Accident Analysis \& Prevention, 94, 8-17. https://doi.org/10.1016/j.aap.2016.05.014

Man, S. S., Chan, A. H. S., \& Wong, H. M. (2017). Risk-taking behaviors of Hong Kong construction workers - A thematic study. Safety Science, 98, 25-36.

https://doi.org/10.1016/j.ssci.2017.05.004

Manuele, F. A. (2005). Risk assessment and hierarchies of control. Professional Safety, 50(5), 33-39.

Marzouk, M., \& Ali, H. (2013). Modeling safety considerations and space limitations in piling operations using agent based simulation. Expert Systems with Applications, 40(12), 48484857. https://doi.org/10.1016/j.eswa.2013.02.021

McFadden, A. (2015). The impact of co-workers on safety outcomes: Comparing models of mediation, moderation, and incremental effects (Dissertation, Clemson University).

Meliá, J. L., Mearns, K., Silva, S. A., \& Lima, M. L. (2008). Safety climate responses and the perceived risk of accidents in the construction industry. Safety Science, 46(6), 949-958. https://doi.org/10.1016/j.ssci.2007.11.004

Milazzo, M. F., Spasojević-Brkić, V., \& Ancione, G. (2015). Safety in crane operations: An overview on crane-related accidents. In Proceedings of the $6^{\text {th }}$ International Symposium on Industrial Engineering (SIE 2015). Belgrade, Serbia.

Mohamed, S. (2002). Safety climate in construction site environments. Journal of Construction Engineering and Management, 128(5), 375-384. https://doi.org/10.1061/(ASCE)0733-9364(2002)128:5(375)

Mueller, L., DaSilva, N., Townsend, J., \& Tetrick, L. (1999). An empirical evaluation of competing safety climate measurement models. In Proceedings of the Annual Meeting of the Society for Industrial and Organizational Psychology. Atlanta, GA.

NIOSH. (2018). Hierarchy of controls. Retrieved from https://www.cdc.gov/niosh/topics/hierarchy/

OSHA. (2004). Injury \& Illness Recordkeeping Forms - 300, 300A, 301.

Randles, V. (2009). PPE matters. A report on attitudes towards Personal Protective Equipment in the construc- tion industry. Retrieved from http://solutions.3m. com/3MContentRetrievalAPI/BlobServlet?lmd=1235730447 000\&locale $=$ en_GB\&univid $=1180609729108 \&$ fallback $=$ true \&assetType=MMM_Image\&blobAttribute=ImageFile\&place $\mathrm{Id}=7 \mathrm{BC} 6 \mathrm{E} 48 \mathrm{~B} 1800 \mathrm{BAE} 180 \mathrm{~A} 88 \mathrm{EBDDE} 34 \mathrm{DE} 24 \&$ version $=\mathrm{cu}$ rrent

Rayner, K. (1975). The perceptual span and peripheral cues in reading. Cognitive Psychology, 7(1), 65-81. https://doi.org/10.1016/0010-0285(75)90005-5

Rebbitt, D. (2014). Pyramid power: A new view of the great safety pyramid. Professional Safety, 59(9), 30-34.

Reyes, A. (2014). Lost time accident. Retrieved from https://www.escservices.com/2014/08/19/lost-time-accident/

Roberts, D. S., \& Geller, E. S. (1996). An "actively caring” model for occupational safety: A field test. Applied and Preventive Psychology, 4(1), 53-59.

https://doi.org/10.1016/S0962-1849(05)80051-4

Rousseau, D. M., \& Fried, Y. (2001). Location, location, location: Contextualizing organizational research. Journal of Organizational Behavior, 22(1), 1-13. https://doi.org/10.1002/job.78

Sawacha, E., Naoum, S., \& Fong, D. (1999). Factors affecting safety performance on construction sites. International Journal of Project Management, 17(5), 309-315.

https://doi.org/10.1016/S0263-7863(98)00042-8

Sawhney, A., Bashford, H., Walsh, K., \& Mulky, A. R. (2003). Agent-based modeling and simulation in construction. In Proceedings of the 2003 Winter Simulation Conference (pp. 1541-1547). New Orleans, Louisiana.

Sharpanskykh, A., \& Stroeve, S. H. (2011). An agent-based approach for structured modeling, analysis and improvement of safety culture. Computational and Mathematical Organization Theory, 17(1), 77-117. https://doi.org/10.1007/s10588-011-9083-9

Tam, C. M., \& Fung, I. W. H. (1998). Effectiveness of safety management strategies on safety performance in Hong Kong. Construction Management and Economics, 16(1), 49-55. https://doi.org/10.1080/014461998372583

Tucker, S., Chmiel, N., Turner, N., Hershcovis, M. S., \& Stride, C. B. (2008). Perceived organizational support for safety and employee safety voice: The mediating role of coworker support for safety. Journal of Occupational Health Psychology, 13(4), 319. https://doi.org/10.1037/1076-8998.13.4.319

Turner, N., Chmiel, N., Hershcovis, M. S., \& Walls, M. (2010). Life on the line: Job demands, perceived co-worker support for safety, and hazardous work events. Journal of Occupational Health Psychology, 15(4), 482.

https://doi.org/10.1037/a0021004

UAW. (2001). Warning! Behavior-based safety can be hazardous to your health and safety program! Retrieved from http://www. uawlocal974.org/BSSafety/Warning!_Behavior-Based_Safety_ Can_Be_Hazardous_To_Your_Health_and_Safety_Program!. pdf

UMSL. (2014). OSHA fact sheet: Personal Protective Equipment. Retrieved from http://www.umsl.edu/ environment/training/ oshappe.html

UNISDR. (2009). Terminology on disaster risk reduction. Retrieved from https://www.unisdr.org/files/7817_UNISDRTerminologyEnglish.pdf

Walsh, K. D., \& Sawhney, A. (2004). Agent-based modeling of worker safety behavior at the construction workface. In Proceedings of the $12^{\text {th }}$ Annual Conference of the International Group for Lean Construction (pp. 779-792). Helsingør, Denmark. 
Watson, G. W., Scott, D., Bishop, J., \& Turnbeaugh, T. (2005). Dimensions of interpersonal relationships and safety in the steel industry. Journal of Business and Psychology, 19(3), 303-318. https://doi.org/10.1007/s10869-004-2230-2

Wilensky, U. (1999). NetLogo. Retrieved from http://ccl.northwestern.edu/netlogo/

Wilensky, U. (2015). An introduction to agent-based modeling: modeling natural, social, and engineered complex systems with NetLogo. The MIT Press.

\section{Appendix}

Table A.1. The attributes of crane agent

\begin{tabular}{|clcc|}
\hline No. & Attribute & \multicolumn{1}{c|}{ Value } & \multicolumn{1}{c|}{ Definition } \\
\hline 1 & length & $\mathrm{U}(5,30)$ & The length of the crane jib \\
2 & heading & $\mathrm{U}\left(-90^{\circ}, 90^{\circ}\right)$ & $\begin{array}{l}\text { The orientation of the } \\
\text { crane jib }\end{array}$ \\
\hline
\end{tabular}

Note: $\mathrm{U}(\mathrm{a}, \mathrm{b})$ refers to a continuous uniform distribution with a minimum of $a$ and a maximum of $b$.
Table A.2. The attributes of environment (patches)

\begin{tabular}{|cccl|}
\hline No. & Attribute & Value & \multicolumn{1}{c|}{ Definition } \\
\hline 1 & danger & o or 1 & $\begin{array}{l}\text { Describe whether the patch } \\
\text { is hit by the fallen load from } \\
\text { crane jib }\end{array}$ \\
\hline
\end{tabular}

Note: In the present model, the size of one patch is one square meter.

Table A.3. The attributes of worker agents

\begin{tabular}{|c|c|c|c|}
\hline No. & Attribute & Default Value & Definition \\
\hline 1 & working-speed & $\mathrm{N}(1,0.05)$ (sq.m/hour) & Describe the productivity of worker agents \\
\hline 2 & safety-awareness & $\mathrm{N}($ mean.SA, 5) & $\begin{array}{l}\text { Describe the likelihood of worker agents walking in hazardous } \\
\text { area }\end{array}$ \\
\hline 3 & PPE-status & 0 or 1 & Describe the PPE-wearing status of worker agents \\
\hline 4 & individual-recordable-incident & 0 & $\begin{array}{l}\text { Record the number of recordable incidents suffered by worker } \\
\text { agents }\end{array}$ \\
\hline 5 & individual-lost-time-incident & 0 & $\begin{array}{l}\text { Record the number of lost-time incidents suffered by worker } \\
\text { agents }\end{array}$ \\
\hline
\end{tabular}

Note: $\mathrm{N}(\mathrm{a}, \mathrm{b})$ refers to a normal distribution with mean a and standard deviation $\mathrm{b}$.

Table A.4. Global variables of the model

\begin{tabular}{|llcl|}
\hline No. & \multicolumn{1}{c}{ Variable } & $\begin{array}{c}\text { Default } \\
\text { value }\end{array}$ & \multicolumn{1}{c|}{ Definition } \\
\hline 1 & hazard-level & 5 & The likelihood of occurring a dropped-load incident \\
2 & mean.SA & 75 & The mean value of safety awareness of worker agents \\
3 & Num-NoPPE & 5 & The number of worker agents not wearing Personal Protective Equipment (PPE) \\
4 & SupportA & False & Whether worker agents provide SupportA (warn co-workers to leave hazardous area) \\
5 & SupportB & False & Whether worker agents provide SupportB (remind co-workers to wear PPE) \\
6 & recordable-incident & 0 & Record the number of recordable incidents happened in the construction site \\
7 & lost-time-incident & 0 & Record the number of lost-time incidents happened in the construction site \\
8 & fatal-incident & 0 & Record the number of fatal incidents happened in the construction site \\
\hline
\end{tabular}

